\title{
DINAMISMO DO MERCADO DE TRABALHO FORMAL E MOBILIDADE ESPACIAL DETRABALHADORES
}

\author{
Rodrigo Nunes Ferreira* \\ Ralfo Matos
}

\section{Resumo}

Considerando o atual período intercensitário, quando a principal fonte de dados municipais apresenta-se em muitos aspectos desatualizada, busca-se explorar novas questões sobre a mobilidade espacial através das possibilidades oferecidas pela base de dados da Rais e Raismigra. Este trabalho apresenta uma análise do dinamismo do mercado de trabalho dos municípios brasileiros nos últimos dez anos, e seu impacto na mobilidade espacial de trabalhadores no mercado formal. Com base na evolução das taxas de variação anual do emprego formal entre 1998 e 2006, fez-se uma seleção dos municípios mais dinâmicos. Foram considerados como tais aqueles que apresentaram crescimento anual acima da média nacional em pelo menos seis dos oito períodos analisados. Confirmando as tendências de crescimento demográfico registradas nos últimos anos, observa-se que os municípios que atendem a esse quesito estão mais presentes nas regiões Norte e Centro-Oeste e entre os municípios que possuem entre 20 mil e 500 mil habitantes. Os dados da mobilidade espacial no mercado formal confirmam a tendência de dinamismo dos municípios selecionados, tendo em vista que nestes, quando comparados com os demais municípios, é maior a participação no total de empregados em 2005 daqueles que tiveram experiência no mercado formal em outros municípios nos cinco anos anteriores. Os dados sobre a origem desses trabalhadores mostram que os fluxos municipais mais expressivos, acima de cinco mil registros, são de curta distância e localizados dentro de áreas metropolitanas. Entre os fluxos intermediários, entre mil e cinco mil registros, surgem fluxos de longa distância, destacando aqueles que têm como origem as grandes capitais da região Sudeste. Destacam-se ainda diversos fluxos direcionados a municípios dinâmicos das regiões metropolitanas de São Paulo, Campinas e Belo Horizonte, além dos que apontam para dinâmicas sub-regionais, como entre Londrina e Maringá e os direcionados para municípios do norte fluminense (Campos dos Goytacazes eMacaé).

Palavras-chave: Migração; Mercado de trabalho; Mobilidade espacial.

\footnotetext{
*LESTE/IGC/UFMG.

•Professor do Centro Universitário de Belo Horizonte (UNI-BH), mestre em Geografia.

Cadernos do Leste 


\section{1- INTRODUÇÃO}

Pode-se parametrizar a análise recorrendo ao princípio estruturalista de que as migrações internas são historicamente condicionadas, como resultado de um processo mais geral de mudanças, do qual elas estão associadas (SINGER, 1975, p 31:33), mas que em determinadas circunstâncias elas podem também constituir em fator de condicionalidade,uma vez que podem influir mais ou menos decisivamente nos mercados de trabalho local. Isso não elimina as preocupações com os limites das configurações históricas que dão sentido a determinados fluxos migratórios, inserindo-os no contexto de produção social do espaço.

As novas tendências emergentes do processo de reestruturação produtiva impõemfortes modificações na dinâmica do território, e a compreensão dessa realidade, cada vezmais complexa, requer novos instrumentos conceituais. É neste sentido que Bertha Becker (2004, p. 13) destaca o rompimento, nas últimas décadas, com o clássico padrão cepalino de análise do tipo centroperiferia, que servira como base para compreensão da dinâmica da produção do território nacional. Hoje tornou-se insuficiente, já que as periferias não são mais apenas consumidoras de produtos industrializados e exportadoras de recursos para os centros.

No cenário de crescente abertura da economia nacional o aumento da competitividadee crescente importância da inovação tenderiam a reforçar, sob certos aspectos, o processo de reconcentração nas grandes aglomerações (BENKO; LIPIETZ, 1994; VELTZ, 1994; SCOTTT et al., 2001). A própria busca pela proximidade em diversas atividades modernas joga um papel decisivo na decisão locacional dos agentes econômicos (RALLET, 2003; TORRE, 2003), aumentando a importância das economias de urbanização ${ }^{1}$.

Entretanto alguns estudos destacam que este novo contexto econômico tem favorecidoa fragmentação da economia nacional do ponto de vista espacial, incentivada pela atuação das políticas de descompressão do desenvolvimento regional dos anos de 1970 e, mais tarde, pela saída de muitas empresas do sudeste em busca de ganhos operacionais em outras regiões do país. Tal visão destaca a importância crescente da inserção dinâmica de "illhas de eficiência" ligadas diretamente ao mercado externo, apontando para a natureza fragmentada e heterogênea, em termos espaciais, do desenvolvimento econômico brasileiro, principalmente na década de 1990. (PACHECO, 1996).

\footnotetext{
${ }^{1}$ No caso específico do Brasil, Tinoco (2001) apresenta evidências que apontam para permanência da RegiãoMetropolitana de São Paulo como importante base industrial, principalmente para as empresas que se destacam em termos de investimento em tecnologia, fruto da necessidade que estas empresas têm de uma "localização que permita e facilite as relações de troca de informações, de conhecimentos, que são a base das possibilidades inovadoras e, conseqüentemente, de acumulação na economia atual” (p. 62).
} 
Essa tendência de fragmentação também estaria sendo estimulada pelastransformações no campo brasileiro, mediante a modernização das atividades ligadas ao agronegócio e o impulso dado pela crescente participação das commodities agrícolas na pautade exportação brasileira, o que incentiva a expansão da fronteira agrícola no Centro-Oeste brasileiro. $\left(\right.$ GRAZIANO DA SILVA, 1999) ${ }^{2}$

Sabóia (2001) destaca que em um contexto de modernização industrial combinado com baixo crescimento econômico durante a década de 1990, os diferenciais salariais, a guerra fiscal, a implantação do Mercosul e o próprio nível de infraestrutura e de desenvolvimento local serviram de atrativo para que o emprego e a produção industrial sofressem determinados rearranjos espaciais. $\mathrm{O}$ autor destaca o deslocamento do emprego industrial: i) para a Região Sul, especialmente para o Paraná, nos setores industriais modernos e tradicionais; ii) para a Região Nordeste, em setores tradicionais, com ênfase no Estado do Ceará, onde a guerra fiscal foi muito acirrada, resultando na instalação e deslocamento de empresas em busca de menores salários e maiores benefícios fiscais; iii) para a Região CentroOeste, que recebeu parcela do emprego, em segmentos tradicionais e debaixo nível de desenvolvimento, ligados ao deslocamento da fronteira agrícola, beneficiadospelo aumento da oferta de matérias-primas e pelos baixos salários. Do ponto de vista da distribuição espacial da população também é possível apontar tendências gerais do processo de reestruturação espacial na dinâmica produtiva, mediante análise do processo de distribuição espacial da população. Se a concentração não foi somentedas atividades produtivas, mas também populacional, não há dúvida de que no debate atual sobre a questão da desconcentração a variável demográfica deve ser tratada como elemento chave para entender tal processo (MATOS, 1995). A dinamização da rede urbana, com significativa melhoria das infraestruturas dos centros intermediários, tem favorecido a expansão da produção em espaços alternativos, estimulando o adensamento da rede urbana brasileira e os vínculos de interdependência e complementaridade entre cidades estratégicas postadas nas diferentes partes do sistema (MATOS, 2002). A generalização das mudanças nadinâmica populacional, em face do avanço da transição demográfica, influi na redução dos níveis de pressão do campo sobre a cidade, implicando radical alteração dos fluxos migratórios, de mais de meio século de movimentos de tipo campo-cidade, já a partir da década de 1980, predominam os fluxos urbano-urbano acompanhando o padrão de desconcentração. Assim, a migração torna-se também um elemento central no entendimentodo processo de

\footnotetext{
${ }^{2}$ Esse "Novo Rural", compõe-se basicamente de três grandes grupos de atividades: a) um agropecuária moderna, baseada em commodities e intimamente ligada às agroindústrias; b) um conjunto de atividades não agrícolas, ligadas à moradia, ao lazer e a várias atividades industriais e de prestação de serviços; c) um conjunto de "novas" atividades agropecuárias, localizadas em nichos especiais de mercados (Graziano da Silva , 1999).
}

Cadernos do Leste 
dispersão espacial econômico-populacional deste a década de 1970. Os resultados dos censos de 1991 e 2000 mostraram uma expansão e diversificação da rede urbana nacional, com o crescimento de capitais regionais e sub-regionais, bem como oaumento da população urbana em grande número de cidades de diferentes tamanhos,conformando novos espaços da produção econômica e da imigração. Esses espaços assumemimportância crescente, já que são capazes tanto de absorver quanto de reter grande parte dosfluxos migratórios que, anteriormente, teriam como destino as grandes concentrações metropolitanas, ratificando o caráter descentralizado da urbanização brasileira contemporânea. $\quad$ Considerando o atual período intercensitário, quando a principal fonte de dados municipais apresenta-se em muitos aspectos desatualizada, busca-se explorar em sequêncianovas questões sobre a mobilidade espacial de pessoas por meio das possibilidades oferecidaspela base de dados da Rais e Raismigra.

A

metodologia proposta para definição de municípios dinâmicos baseia-se numa análise da variação no estoque municipal de trabalhadores no mercado formal nos últimosdez anos. Tendo definido o grupo de municípios dinâmicos, busca-se fazer uma análise da mobilidade espacial de trabalhadores no mercado formal, analisando a distribuição e as características dos fluxos direcionados para estes municípios.

\section{2 - A BASE DE DADOS RAIS}

Os dados da RAIS resultam de registros administrativos do Ministério do Trabalho voltados ao acompanhamento do mercado de trabalho formal, arrecadação de contribuições edistribuição de benefícios previstos na legislação trabalhista. Instituída em 1975, a RAIS pode ser considerada um censo administrativo sobre o mercado de trabalho, na medida em que todas as organizações legais (privadas e públicas) são obrigadas a declará-la anualmente.

Os dados, resultantes da declaração obrigatória das empresas, mostram características básicas dos empregados. O tratamento dos dados permite sua desagregação até o nível municipal, discriminando subatividades econômicas e ocupações. Tais informações são disponibilizadas segundo estoque (número de empregos) e movimentação de mão-de-obra empregada (admissões e desligamentos) por sexo, faixa etária, grau de instrução, rendimentomédio e faixas de rendimentos em salários mínimos. A partir dos anos 1990 a cobertura da RAIS, segundo o Ministério do Trabalho, tem oscilado em torno de $90 \%$ do setor formal daeconomia, podendo variar de acordo com a situação urbana ou rural, região (melhor no Sudeste) e porte doestabelecimento (cobertura pior nas pequenas e médias empresas).

A Raismigra é uma base de dados derivada da RAIS, também organizada pelo Ministério 
do trabalho, que, via controle pelo número de inscrição no PIS (Programa de Integração Social), permite o acompanhamento da trajetória geográfica, setorial e ocupacional dos trabalhadores no mercado formal. Neste trabalho, utilizar-se-á do modelo tipo painel de organização da informação, que permite construir uma série longitudinal e comparar a posição do trabalhador ao longo do tempo, possibilitando o estudo da mobilidade,geográfica e setorial, do indivíduo no mercado de trabalho formal ao longo do período analisado.

Por tratar-se de uma fonte alternativa de pesquisa sobre migração, é necessáriodelimitar metodologicamente as diferenças que apresenta em relação ao Censo Demográficodo IBGE, que é a fonte de dados mais tradicional sobre o tema. Diferentemente do censo, a Raismigra permite acompanhar a evolução temporal dos trabalhadores e dos espaços (municípios, estados e regiões). Como o controle é feito pelo número do PIS, é possível identificar todas as características do vínculo empregatício (remuneração, localização, setor, atividade, etc.) de um trabalhador do mercado formal ano aano, mesmo que ele mude de emprego ao longo do período. Assim é possível ter acesso às características do vínculo empregatício ao qual um determinado trabalhador esteve submetidoao longo de todo o período investigado. A principal limitação da Raismigra é sua restrição aomercado formal, e em decorrência, quando o trabalhador se ausenta do mercado formal emum determinado ano, perdem-se as informações sobre essa pessoa.

\section{3 - O CONCEITO DE MIGRANTE UTILIZADO}

Na Raismigra a situação de migrante é dada em função do local de trabalho. Foi investigado para cada vínculo ativo em 2005 o município de localização dos vínculos entre 2000 e 2004, sendo considerado migrante o trabalhador que nos cinco anos anteriores a 2005teve pelo menos um vínculo ativo no mercado formal em um município diferente daquele noqual se encontrava empregado ao final de 2005.

Reconhece-se que o conceito de migrante aqui utilizado guarda diferenças significativas em relação ao que é tradicionalmente definido através dos dados censitários. Ea principal delas é que nem sempre a mudança do local de trabalho implica em mudança dolocal de residência, principalmente nos percursos de curta distância. O mais correto, como opróprio título desse trabalho chama atenção, é tratar de mobilidade espacial do emprego formal. Entretanto, na falta de um termo mais apropriado, e simples, utilizar-se-á o termo "migrante" para definir toda situação em foi verificada mudança no município de localizaçãodo vínculo ao mercado formal.

\section{4 - SELEÇÃO DOS MUNICÍPIOS}


A busca da plena comparação dos dados municipais foi determinante para delimitaçãodos recortes temporais e espaciais. Foi necessário contornar os problemas advindos do intenso processo de emancipação ocorrido ao longo da década de 1990, que teve o último surto em 1997. Optou-se pela utilização dos dados a partir de 1998, e pela exclusão dos municípios que passaram por alteração territorial após 1997. Ao final, dos 5.564 municípios existentes em 2006, foram excluídos da análise 133 municípios emancipados ou fragmentados no período e mais outros 95 que não tinham dados disponíveis para um dos anos analisados. Com isso passou-se a trabalhar com 5.336 municípios (FIG. 1)

\section{Figura 1 - Resultado final da seleção de municípios}

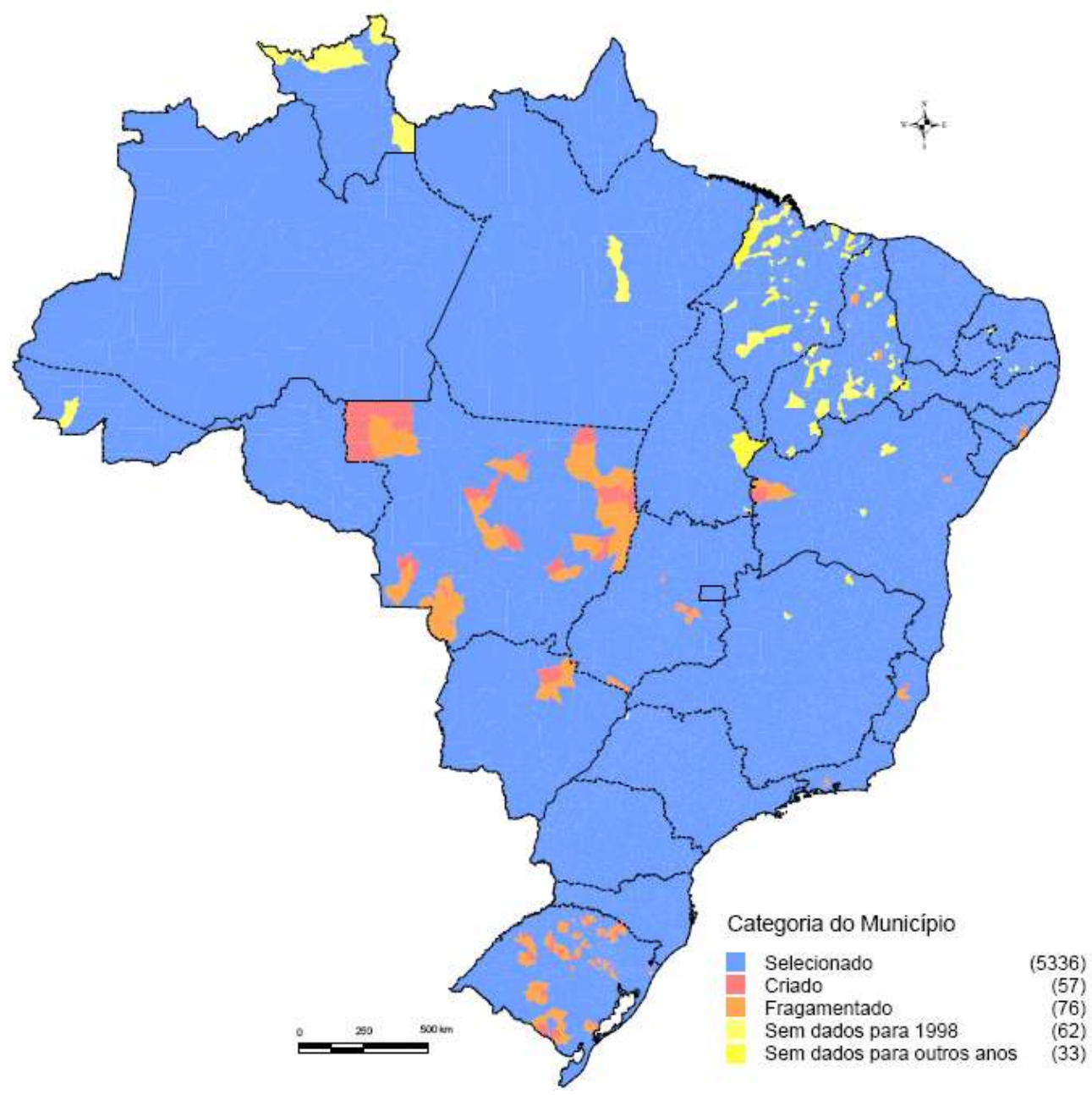




\section{5 - DEFINIÇÃO DOS MUNICÍPIOS DINÂMICOS}

Para investigar a questão da mobilidade espacial foi necessário primeiro definir um grupo mais restrito de municípios. Com base na evolução das taxas de crescimento anuais doemprego formal entre 1998 e 2006, fez-se uma seleção dos municípios mais dinâmicos. Foi definido como dinâmico o município que manteve um crescimento consistente do empregono mercado formal de trabalho no período. Isto é, aqueles municípios que entre 1998 e 2006tiveram variações anuais positivas no emprego formal acima da variação média nacional parao mesmo ano em pelo menos seis dos oito períodos analisados, o que dá origem, portanto, aum grupo de municípios que apresentam as maiores taxas de crescimento no período, como se observa nos dados apresentados no GRÁfICO 1. Tal critério mostrou-se mais efetivo quea simples média de crescimento no acima da média nacional no período, o que incluiria quase $80 \%$ dos municípios existentes. Pelo critério utilizado 1.185 municípios foram selecionados (FIG. 2).

Gráfico 1: Variação anual do emprego formal no período 1995-2006 por grupo de municípios dinâmicos e Brasil

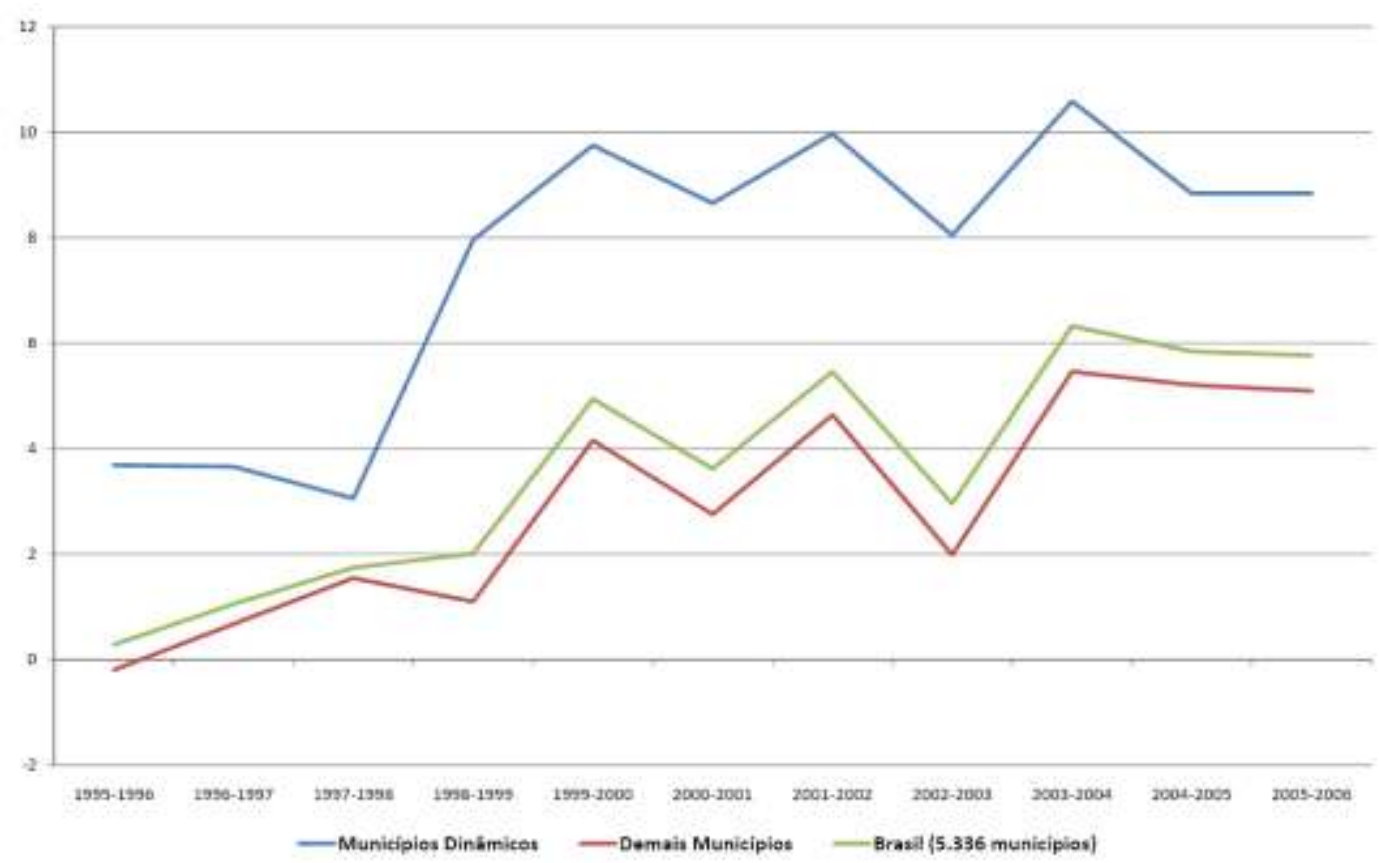

Fonte: Ministério do Trabalho/RAIS

FIGURA2-Municípiosbrasileirosportotaldeperíodosdevariaçõesanuaisdoemprego formal acima da média nacional para o anono período 1998-2006.

Cadernos do Leste 


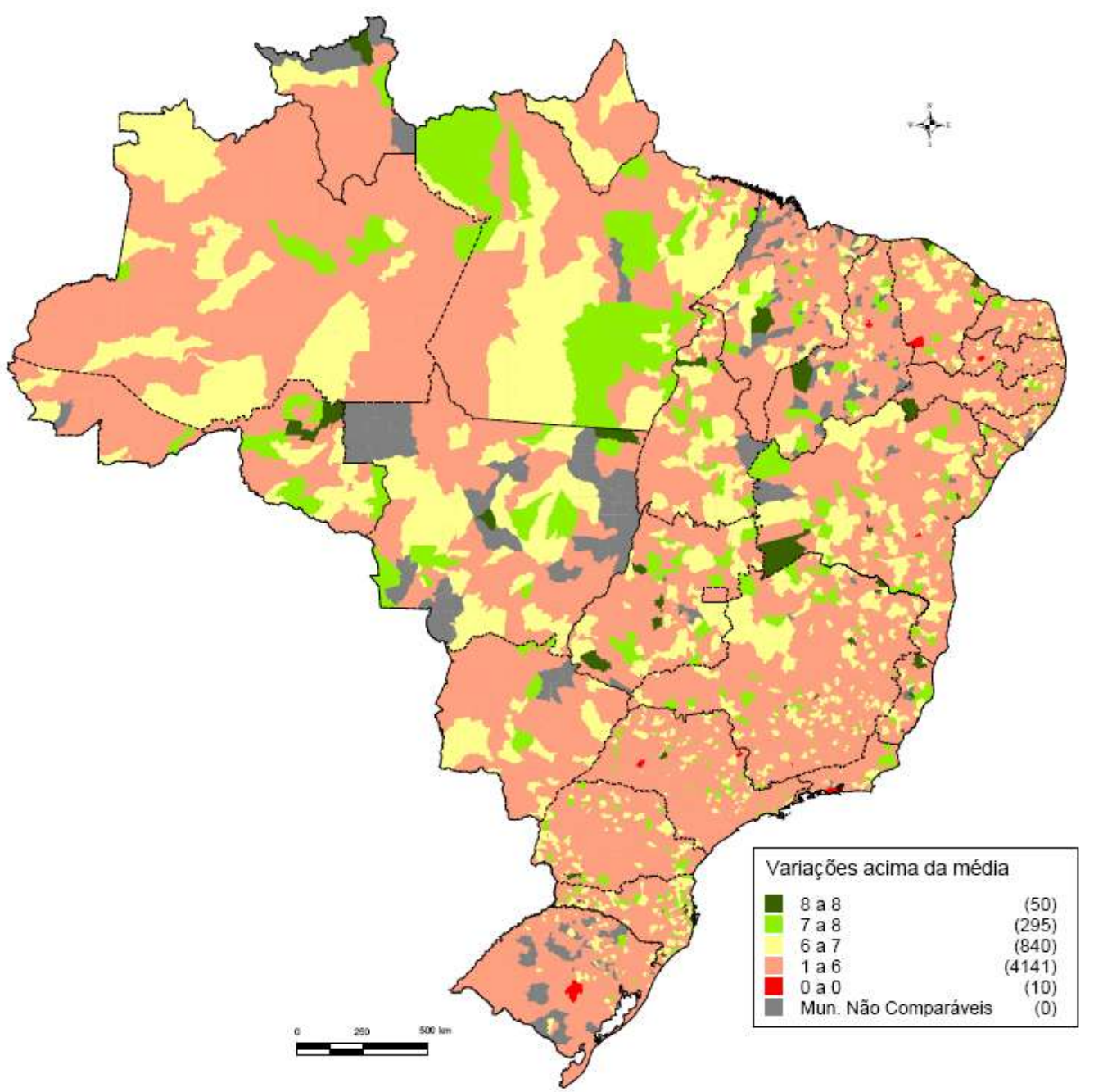

Fonte: MinistériodoTrabalho/RAIS

\begin{tabular}{l|r|r|r|r} 
Tabela 1: Distribuição dos municípios dinâmicos porgrande região \\
\hline Região & Dinâmicos & Não dinâmicos & Total & \multicolumn{2}{c}{$\begin{array}{c}\text { Dinâmicos } \\
(\%)\end{array}$} \\
\hline Centro-Oeste & 121 & 303 & 424 & 28.5 \\
Nordeste & 358 & 1338 & 1696 & 21.1 \\
NorteSudeste & 178 & 262 & 440 & 40.5 \\
Sul & 290 & 1372 & 1662 & 17.4 \\
& 238 & 876 & 1114 & 21.4 \\
\hline Total & $\mathbf{1 1 8 5}$ & $\mathbf{4 1 5 1}$ & $\mathbf{5 3 3 6}$ & $\mathbf{2 2 . 2}$ \\
\hline
\end{tabular}

Fonte: MinistériodoTrabalho/RAIS 
Tabela 2: Distribuição dos municípiosdinâmicos por categoria de porte populacional

\begin{tabular}{l|r|r|r|r}
\hline PortePopulacional & Dinâmicos & \multicolumn{1}{|c|}{$\begin{array}{c}\text { Nãodinâm } \\
\text { icos }\end{array}$} & \multicolumn{1}{c|}{ Total } & \multicolumn{1}{c}{$\begin{array}{c}\text { Dinâmicos } \\
\mathbf{( \% )}\end{array}$} \\
\hline Até 20 mil hab. & 730 & 3.080 & 3.810 & 19.2 \\
De 20mil a menos de 100mil hab. De & 382 & 898 & 1.280 & 29.8 \\
100mil a menos de500mil hab. de 500 & 702 & 141 & 211 & 33.2 \\
mil a menos de 1milhão hab. 1 milhão & 1 & 19 & 21 & 9.5 \\
ou mais hab. & & 13 & 14 & 7.1 \\
\hline Total & $\mathbf{1 . 1 8 5}$ & $\mathbf{4 . 1 5 1}$ & $\mathbf{5 . 3 3 6}$ & $\mathbf{2 2 . 2}$ \\
\hline
\end{tabular}

Fonte: MinistériodoTrabalho/RAIS

É importante verifica $r$ também quais os setores econômicos têm sido responsáveis por esse dinamismo do mercado formal dos municípios selecionados, o que pode apontar arranjos territoriais correlacionados ao dinamismo verificado. Uma primeira aproximação da questão mostra que em termos de setor preponderante não se verifica grandes alterações, prevalecendo as atividades ligadas ao setor público, principalmente no Nordeste e Norte, e ao setor de comércio e serviços (FIG. 3). Convém notar que esses setores são tipicamente urbanos e essenciais para a afirmação de qualquer cidade ao longo do tempo. Por outro lado, é importante também destacar que parte importante dos municípios selecionados tem a indústria de transformação como setor dominante, o que pode ser um indício de que muitos municípios dinâmicos são sustentados por arranjos produtivos locais que impulsionam o crescimento do emprego formal. Também é de destacar a Agropecuária como setor predominante em vários municípios do Centro-Oeste e norte do Tocantins, em subespaços da região do Sudeste (como o sudeste paraense), no oeste baiano e extremo norte de Minas Gerais, além de alguns municípios no oeste paulista. 
Figura 3 - Setor econômico predominante no mercado formal dos municípiosselecionados

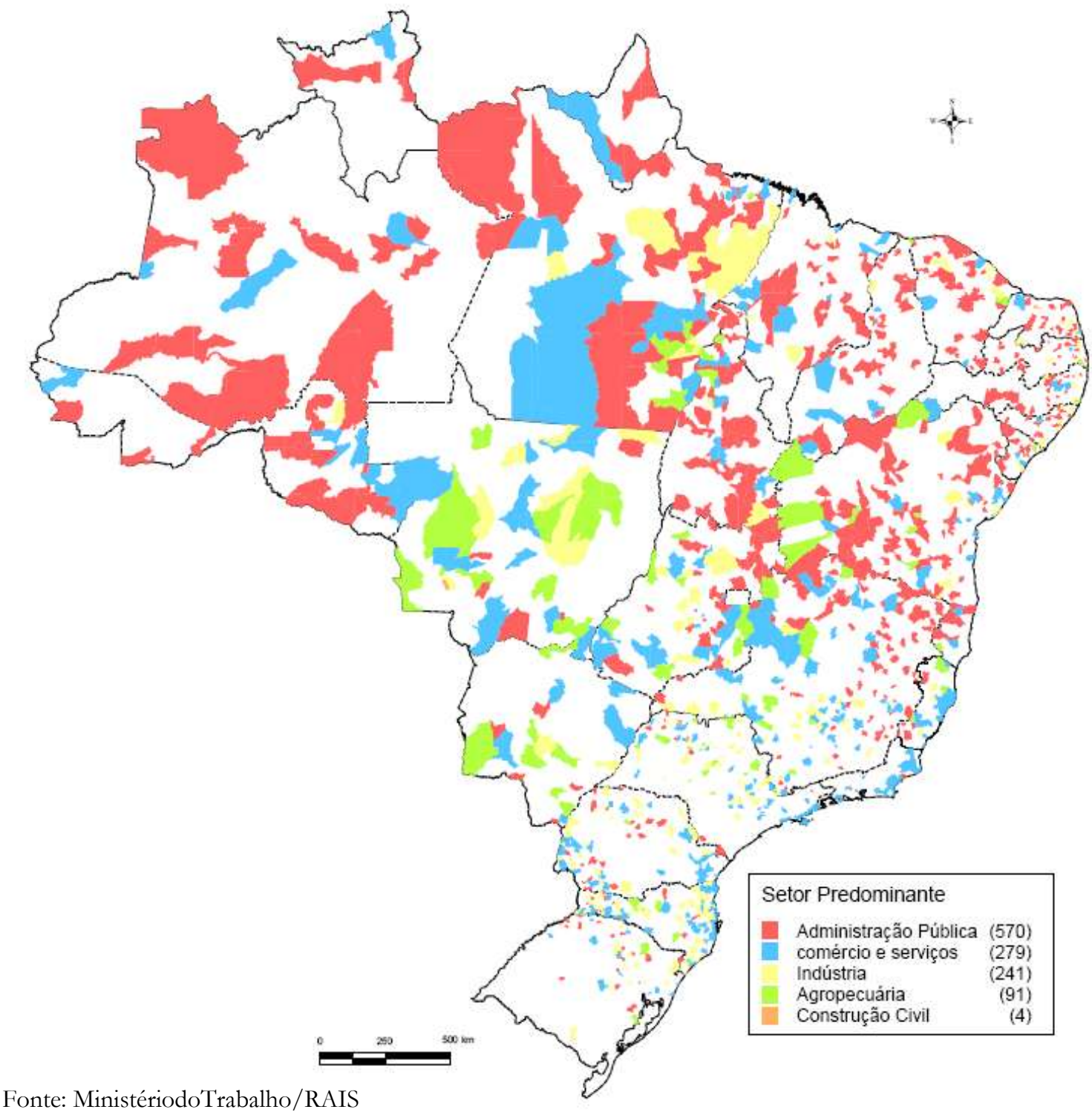

Além do setor econômico predominante, é importante verificar quais os que contribuíram consistentemente para o crescimento do emprego formal nessas localidades. $\mathrm{O}$ mesmo critério utilizado para definir o grupo de municípios dinâmicos foi empregado para definir o setor mais dinâmico em cada município. Assim, para cada setor foi computado ao longo do período o número de vezes em que a variação anual do emprego formal foi superior ao crescimento médio do emprego formal no país. Como em diversos municípios mais de um setor registrou o maior número de variações positivas acima da média, foi necessário utilizar um critério para selecionar o mais dinâmico nesses casos de empate. Para tal priorizou-se a escolha 
dos setores com maior participação no volume total de emprego formal dos municípios dinâmicos ${ }^{3}$.

Os dados da TABELA 3 sintetizam a FIGURA 4 e mostram que o setor de comércio foi destacado no maior número de municípios (33\%), seguido pela indústria (24\%). A análise desagregada por regiões mostra padrões interessantes de serem analisados. No nordeste os setores da administração pública e do comércio foram destacados. Nas regiões norte e centrooeste comparece o setor da agropecuária. Já nas regiões sudeste e sul o destaque é o setor industrial, selecionado como o mais dinâmico em $48 \%$ dos municípios desta última. Estes dados mostram características territoriais específicas do dinamismo do emprego formal, demarcando importantes diferenças na estrutura econômica das regiões que sustentam, a partir de setores específicos, o dinamismo registrado.

Os dados da TABELA 3 sintetizam a FIGURA 4 e mostram que o setor de comércio foi destacado no maior número de municípios (33\%), seguido pela indústria (24\%). A análise desagregada por regiões mostra padrões interessantes de serem analisados. No nordeste os setores da administração pública e do comércio foram destacados. Nas regiões norte e centrooeste comparece o setor da agropecuária. Já nas regiões sudeste e sul o destaque é o setor industrial, selecionado como o mais dinâmico em 48\% dos municípios desta última. Estes dados mostram características territoriais específicas do dinamismo do emprego formal, demarcando importantes diferenças na estrutura econômica das regiões que sustentam, a partir de setores específicos, o dinamismo registrado.

\footnotetext{
${ }^{3}$ Aordemdossetoresutilizadacomoreferência,bemcomoasrespectivasparticipações, foiaseguinte: Indústria(26\%),Serviços(25\%),AdministraçãoPública(19\%),Comércio(18\%),Agropecuária(6\%) Construção Civil （4\%), Extração Mineral (1\%) eServiçosIndustriais (0,7\%). 
Figura 4: setor econômico de destaque nosmunicípios dinâmicos

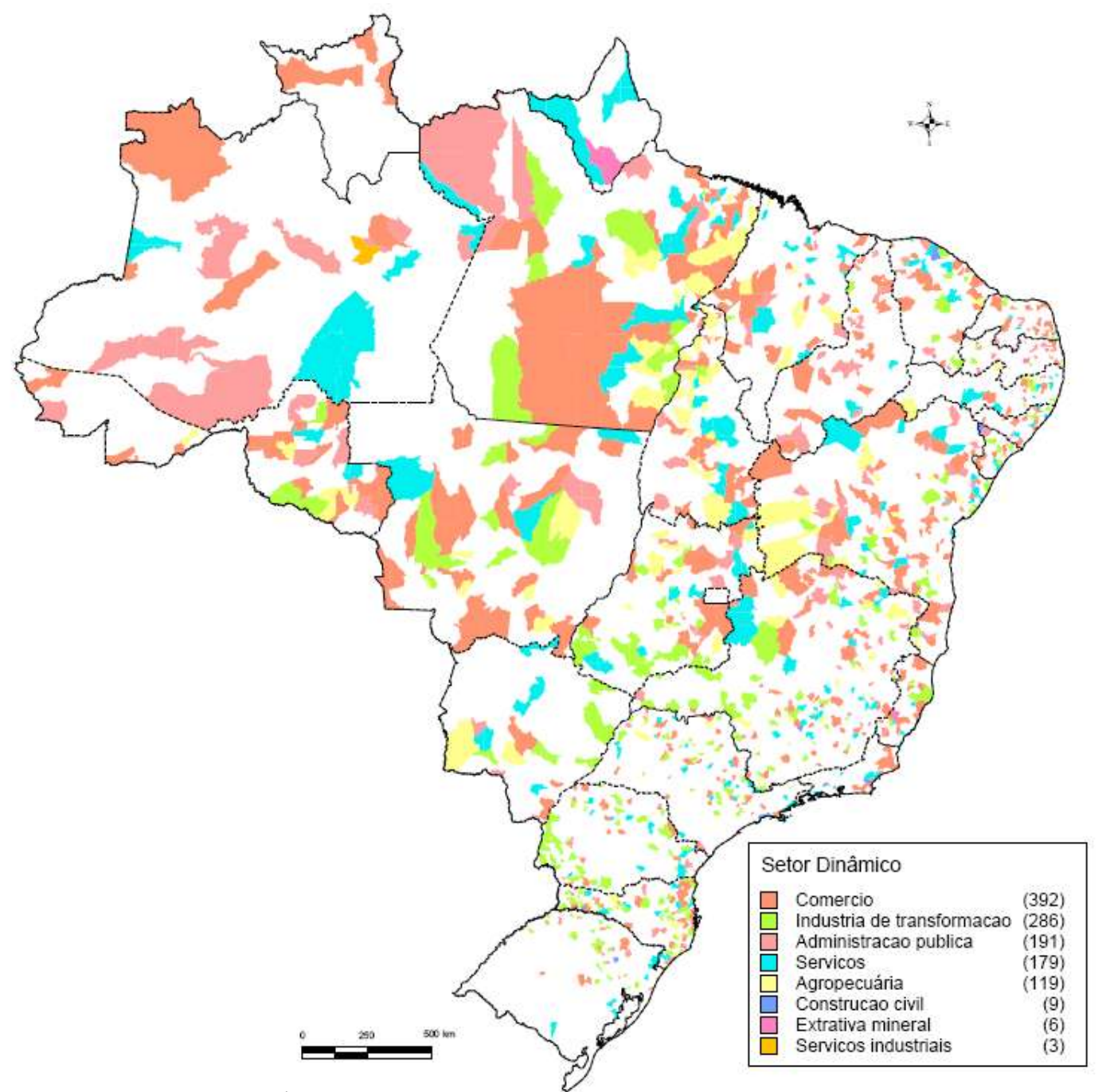

Fonte: MinistériodoTrabalho/RAIS

Cadernos do Leste

Artigos Cientificos

Belo Horizonte, Jan.-Dez. Vol.9, nº, 2009 
Tabela 3: Distribuição dos municípiosdinâmicos por setor econômico dedestaque na geraçãodeempregosnomercadoformal

\begin{tabular}{l|r|r|r|r|r|r}
\hline \multicolumn{1}{c|}{ Setordedestaque } & $\begin{array}{c}\text { Centro- } \\
\text { Oeste }\end{array}$ & Nordeste & Norte & Sudeste & \multicolumn{1}{c|}{ Sul } & \multicolumn{1}{c}{ Total } \\
\hline Agropecuária & 15.7 & 8.7 & 21.9 & 7.6 & 3.4 & 10.0 \\
Extrativa mineral & 0.0 & 0.8 & 0.6 & 0.3 & 0.4 & 0.5 \\
Serviçosindustriais & 0.0 & 0.3 & 0.6 & 0.3 & 0.0 & 0.3 \\
Construção civil & 0.0 & 0.6 & 0.0 & 1.7 & 0.8 & 0.8 \\
Indústria & 24.8 & 12.8 & 7.3 & 28.6 & 47.9 & 24.1 \\
Comércio & 34.7 & 36.3 & 32.0 & 33.4 & 27.7 & 33.1 \\
Serviços & 13.2 & 13.7 & 18.5 & 16.6 & 13.9 & 15.1 \\
Administração pública & 11.6 & 26.8 & 19.1 & 11.4 & 5.9 & 16.1 \\
\hline TotaldeMunicípios & $\mathbf{1 2 1}$ & $\mathbf{3 5 8}$ & $\mathbf{1 7 8}$ & $\mathbf{2 9 0}$ & $\mathbf{2 3 8}$ & $\mathbf{1 . 1 8 5}$ \\
\hline
\end{tabular}

Fonte: MinistériodoTrabalho/RAIS

\section{6-MOBILIDADENOMERCADOFORMAL}

Mas em que medida o dinamismo verificado no mercado formal é capaz de atrair populações migrantes, impulsionando a mobilidade espacial de trabalhadores no mercado formal? A primeira evidência apresentada confirma o fato de que nos municípios considerados dinâmicos os trabalhadores migrantes 4 representavam $26 \%$ dos vínculos ativos, o que equivale a um total de 1.742.777 pessoas, num universo de 6.726.813 trabalhadores registrados ao final de 2005. Nos demais municípios esse percentual, embora menor, é também expressivo, ou seja, 19,6\%, 6.306.866 vínculos num total de 32.107.707. Tomando o valor de $26 \%$ como referência, a TABELA 4 e a FIGURA 5 mostram onde a participação desse tipo de trabalhador supera essa média. Os municípios com maior participação de migrantes estão mais presentes nas regiões Centro Oeste, Sudeste e Sul, chegando nessa última a representar metade dos municípios selecionados.

\footnotetext{
${ }^{4}$ Trabalhadorescompassagempelomercado formal de outro município nos cinco anos anteriores a 2005.
} 
Tabela 4: Municípios dinâmicos comparticipação dos migrantes no merco de trabalhoformal igual ou superior a $26 \%$, por região

\begin{tabular}{l|r|r|r|r}
\hline RótulosdeLinha & $\begin{array}{l}\text { Maioroui } \\
\text { guala26\% }\end{array}$ & $\begin{array}{l}\text { Menorqu } \\
\text { e26\% }\end{array}$ & Totalgeral & $\begin{array}{l}\text { \%acimadam } \\
\text { édiade26\% }\end{array}$ \\
\hline Centro-Oeste & 56 & 65 & 121 & 46.3 \\
Nordeste & 45 & 313 & 358 & 12.6 \\
NorteSudeste & 28 & 150 & 178 & 15.7 \\
Sul & 124 & 166 & 290 & 42.8 \\
& 120 & 118 & 238 & 50.4 \\
\hline Totalgeral & $\mathbf{3 7 3}$ & $\mathbf{8 1 2}$ & $\mathbf{1 1 8 5}$ & 31.5 \\
\hline
\end{tabular}

Fonte: MinistériodoTrabalho/RAIS

Figura 5 - Participação relativa dos trabalhadores migrantes no mercado de trabalho formal dos municípios dinâmicos

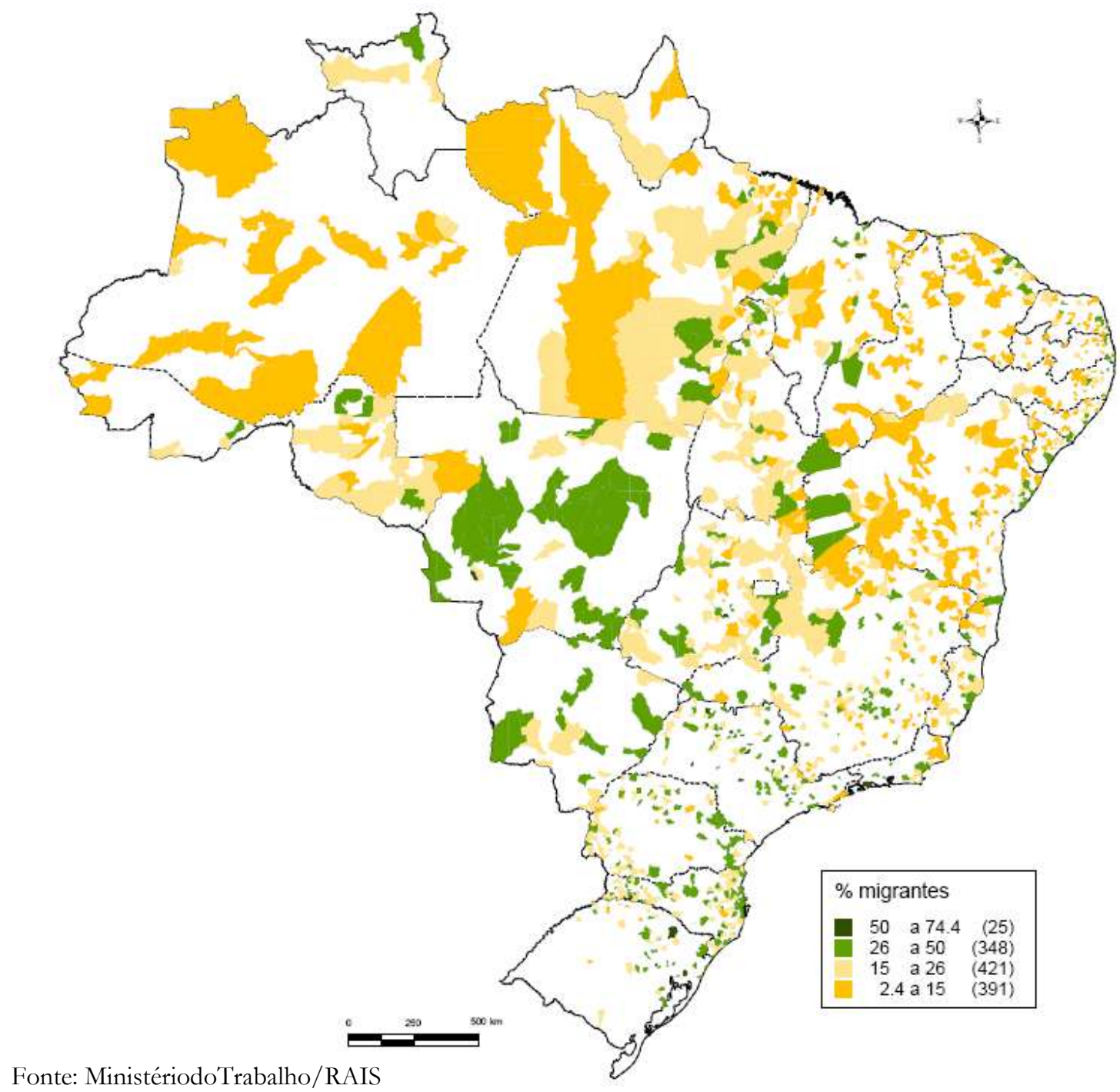

Cadernos do Leste 


\section{1 - Fluxos de mobilidade espacial nomercado de trabalho}

Constatada a tendência de uma maior participação no mercado de trabalho formal dos municípios dinâmicos de trabalhadores com experiência prévia em outros municípios, cabe agora detalhar melhor a origem desses trabalhadores, verificando a estruturação espacial dos fluxos delimitados por esses movimentos. A TABELA 5 apresenta um panorama regional dos fluxos de trabalhadores no mercado formal entre 2000 e 2005. Além dos valores absolutos dos fluxos, dominados pela região Sudeste, é importante verificar as variações relativas, capazes de apontar algumas tendências da mobilidade da mão-de-obra no Brasil. Destaca-se a situação da região Norte, que possui o menor percentual de trabalhadores migrantes provenientes da própria região, na qual a participação de trabalhadores oriundos das regiões Sudeste e Centro Oeste é notável. No geral, a região Norte apresentou trocas positivas com todas as demais regiões, enquanto com o Sudeste, em situação inversa, apresentou trocas negativas.

Como trata-se um grupo mais qualificado do mercado de trabalho, inseridos no mercado de trabalho formal e com experiência prévia em relações formais de trabalho, é de se esperar que esta seja uma tendência que se firma no Brasil, com a crescente atração de trabalhadores mais qualificados para as atividades econômicas que requisitam expansão territorial.

Tabela 5: Distribuição relativa dos fluxos detrabalhadores no mercadoformal por região de origem.

\begin{tabular}{l|r|r|r|r|r}
\hline \multirow{2}{*}{$\begin{array}{c}\text { Regiãode } \\
\text { Origem }\end{array}$} & \multicolumn{5}{|c}{ RegiãodeDestino } \\
\cline { 2 - 6 } & Norte & Nordeste & \multicolumn{1}{c}{ Sudeste } & \multicolumn{1}{c}{ Sul } & $\begin{array}{c}\text { Centro- } \\
\text { Oeste }\end{array}$ \\
\hline Norte & 65,7 & 1,6 & 0,6 & 0,3 & 2,6 \\
Nordeste & 7,8 & 84,1 & 2,2 & 1,3 & 3,2 \\
Sudeste & 14,0 & 11,0 & 93,2 & 7,8 & 11,2 \\
Sul & 2,1 & 1,0 & 1,7 & 88,8 & 5,2 \\
Centro-Oeste & 10,3 & 2,3 & 2,1 & 1,8 & 77,8 \\
\hline
\end{tabular}

Fonte: MinistériodoTrabalho/RAIS

Os dados sobre a origem municipal desses trabalhadores mostram que os fluxos municipais mais expressivos, acima de cinco mil registros, são de curta distância e localizados dentro de áreas metropolitanas (FIGURA 6). Entre os fluxos intermediários, entre mil e cinco mil registros (FIGURA 7), surgem fluxos de longa distância, destacando aqueles que têm 
como origem as grandes capitais da região Sudeste. Destacam-se ainda diversos fluxos direcionados a municípios dinâmicos das regiões metropolitanas de São Paulo, Campinas e Belo Horizonte, além dos que apontam para dinâmicas sub-regionais, como os de Londrina e Maringá e os direcionados para municípios do norte fluminense (Campos dos Goytacazes e Macaé). Os fluxos inferiores a 1.000 trabalhadores, FIGURAS 8, 9 e 10, conformam um emaranhado de redes, que delimitam importantes fluxos de mão-de-obra direcionados para municípios dinâmicos integrantes do nível intermediário da rede urbana. Entretanto, é inviável uma análise mais pormenorizada desses fluxos no âmbito desse trabalho.

\section{Figura 6 - Fluxos de5.000 ou mais trabalhadores comdestinoaosmunicípios dinâmicos}

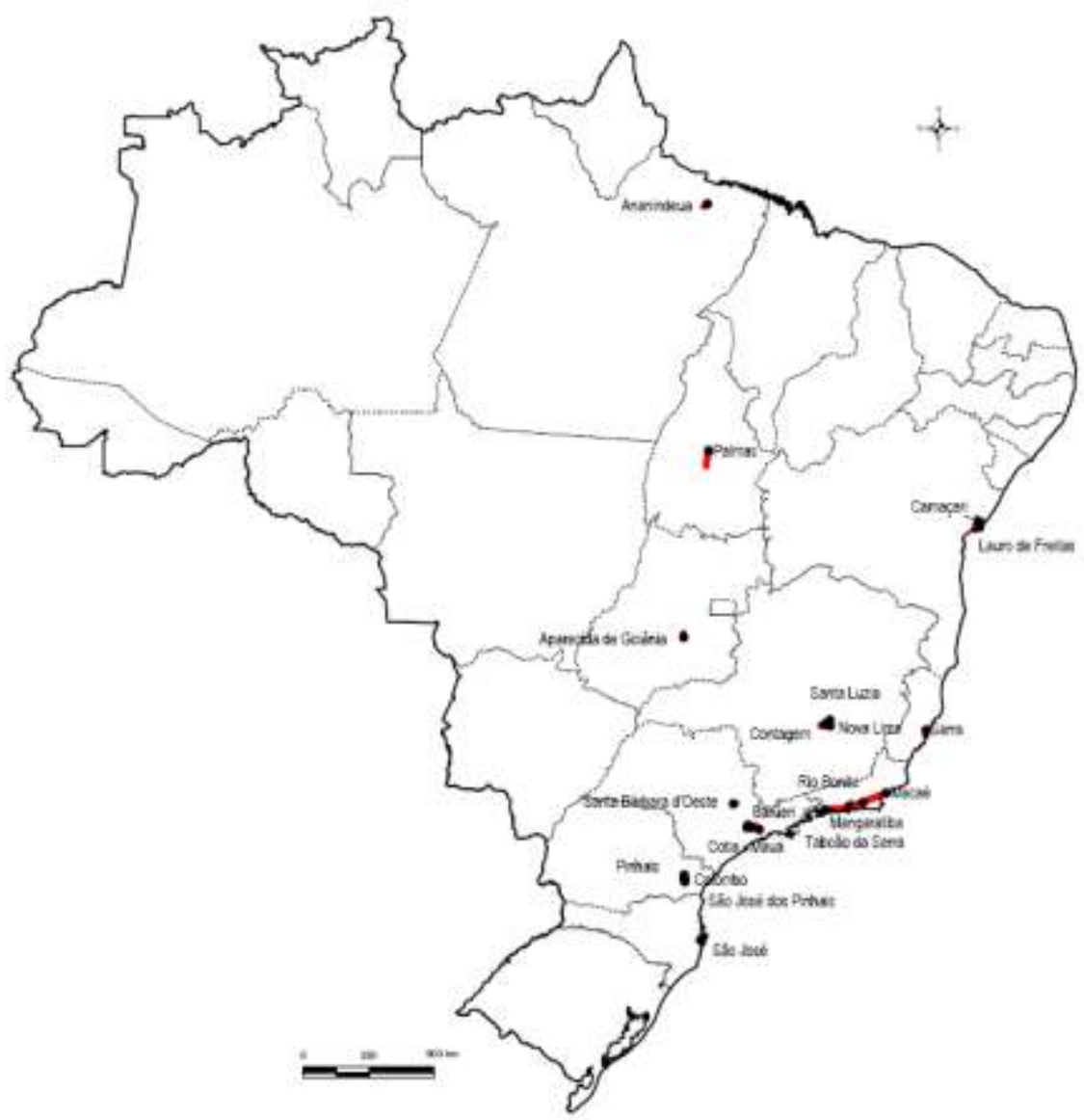

Fonte: 
Figura 7 - Fluxosde 1.000 a menos de 5.000 trabalhadores comdestino aos municípios dinâmicos

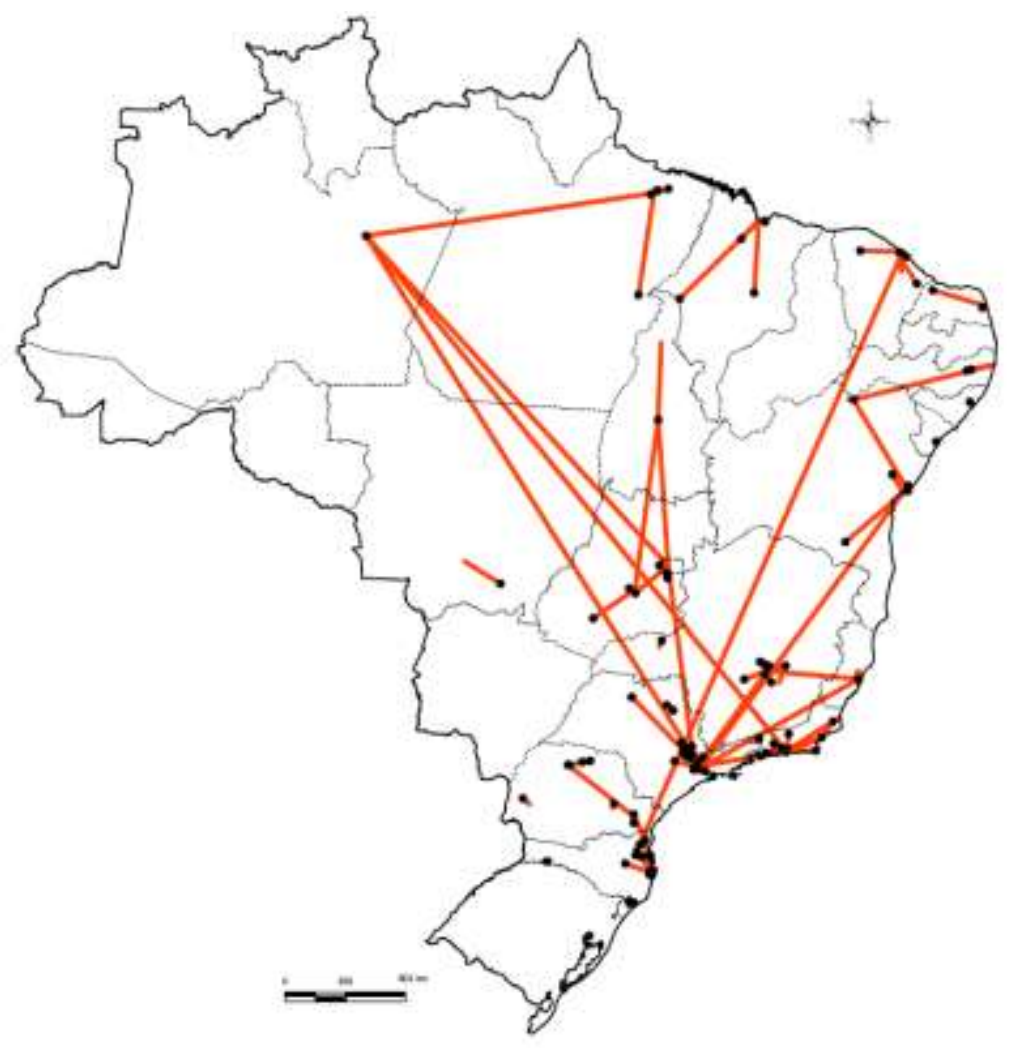

Fonte: MinistériodoTrabalho/RAIS

Figura 8 - Fluxos de 500a menos de 1.000 trabalhadores comdestino aos municípios dinâmicos

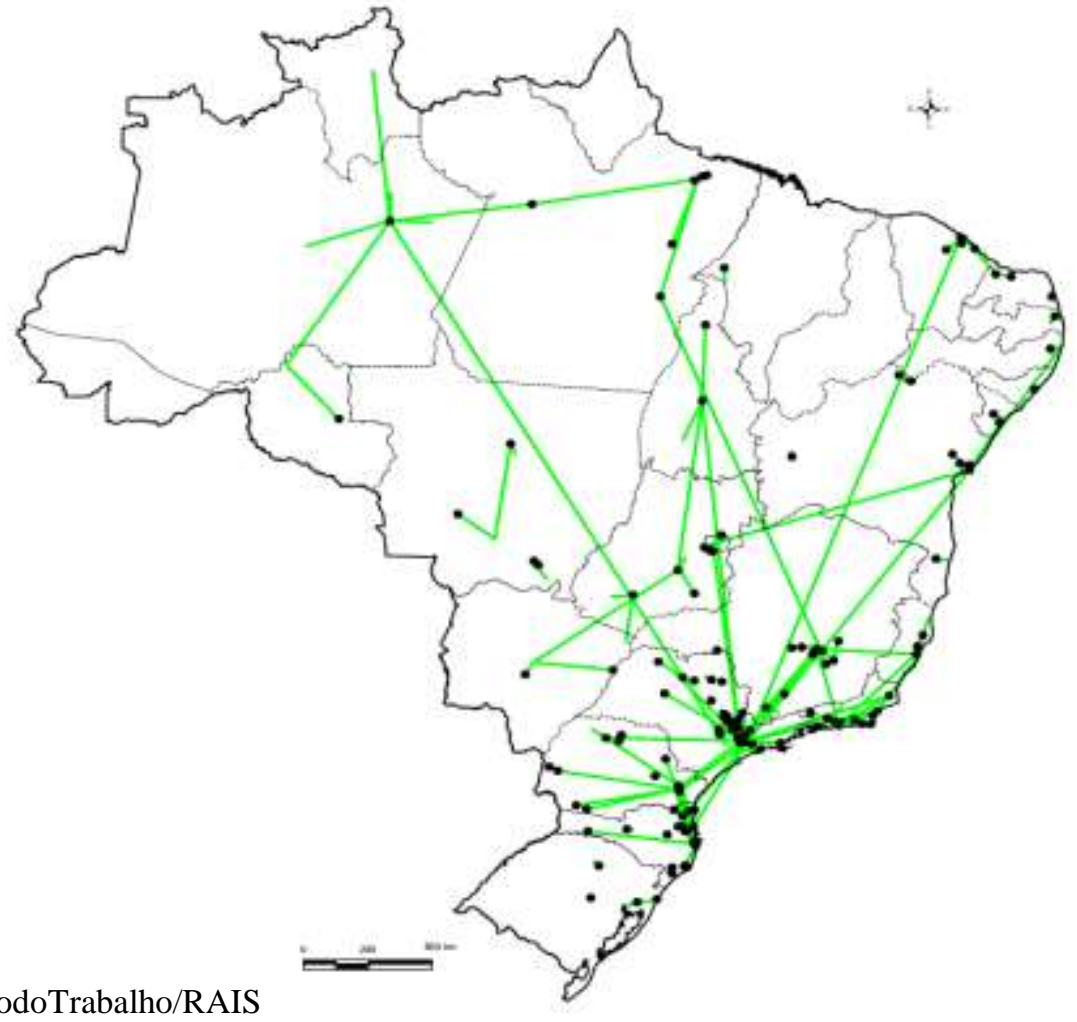

Fonte: MinistériodoTrabalho/RAIS

Cadernos do Leste

Artigos Cientificos

Belo Horizonte, Jan.-Dez. Vol.9, n, 2009 
Figura 9 - Fluxos de 100a menos de 500 trabalhadorescom destino aosmunicípios dinâmicos

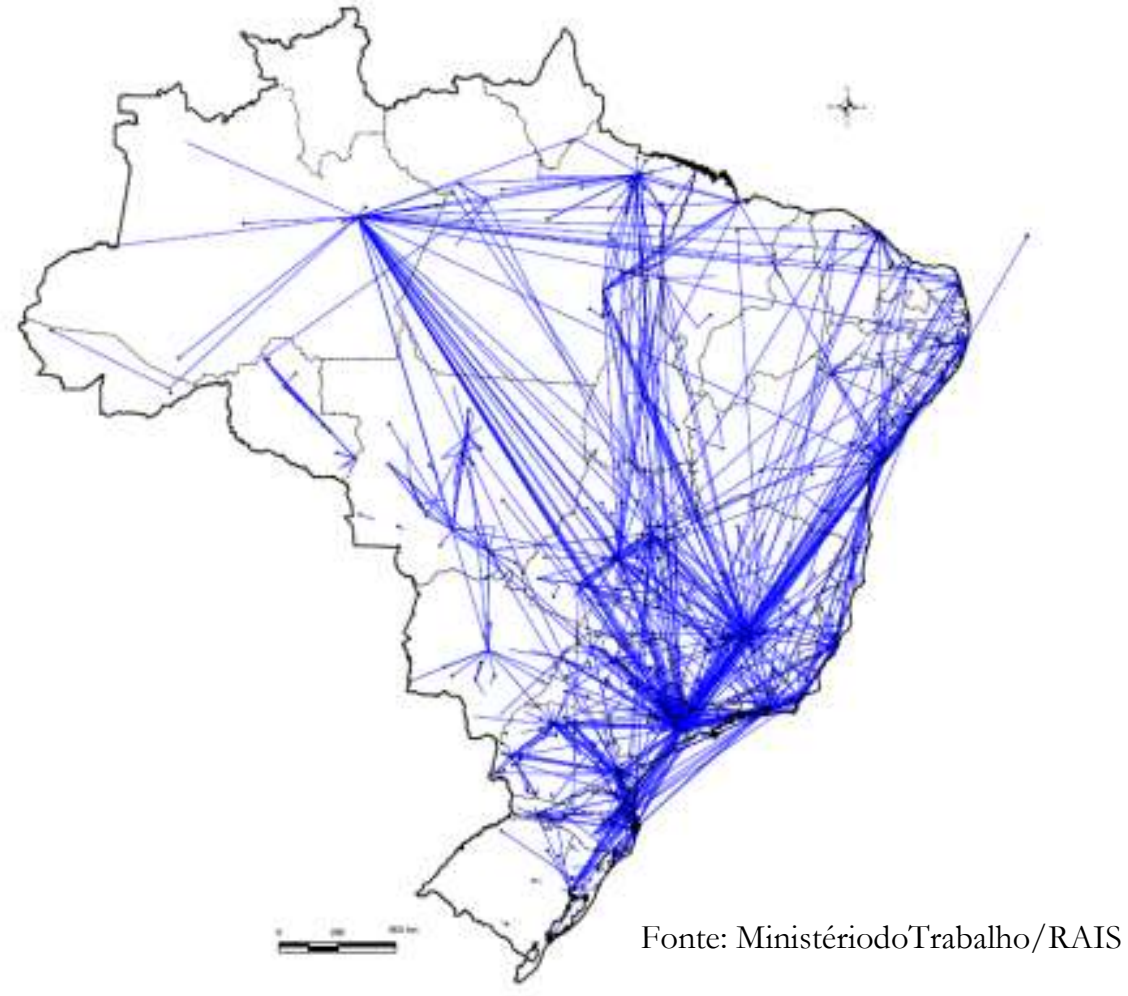

Figura 10 - Fluxos de 50 a menos 100 trabalhadores comdestino aos municípios dinâmicos

Fonte: Ministériodo'Trabalho/RAIS

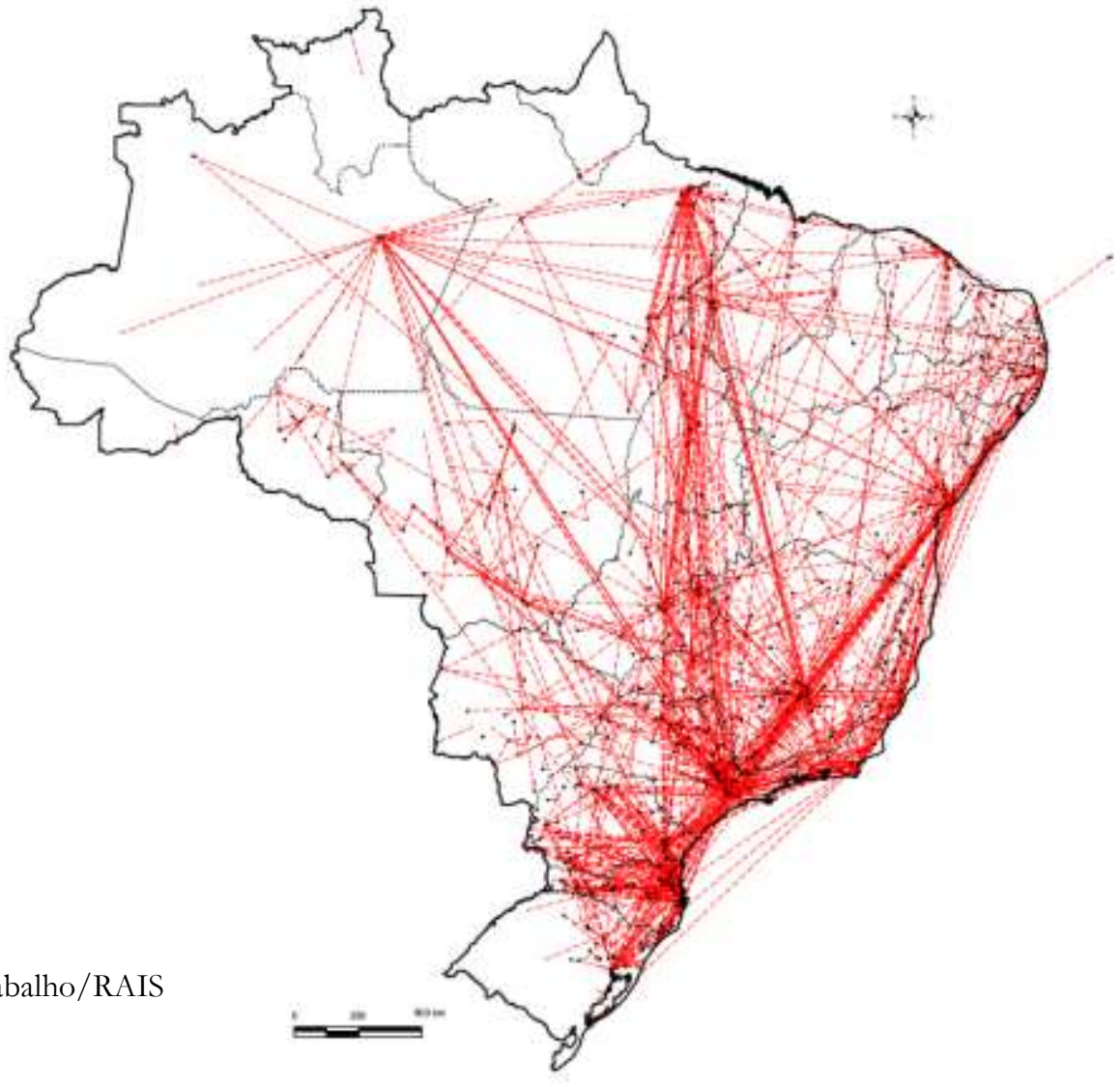

Cadernos do Les

Artigos Cientificos

Belo Horizonte, Jan.-Dez. Vol.9, n, 2009 


\section{2 - Inserção setorial equalificação}

A inserção setorial dos trabalhadores migrantes é um item importante a ser verificado, pois contribui com o entendimento das dinâmicas econômicas que sustentam os fluxos. Outro fator importante a ser investigado é a mobilidade espacial de trabalhares qualificados. Para tal, utiliza-se o nível de escolaridade como uma proxy da qualificação dos trabalhadores. O parâmetro a ser utilizado nas análises desse subitem será a situação encontrada nos demais municípios não selecionados como dinâmicos. As atividades industriais e o setor de serviços se destacam nos municípios dinâmicos como grandes receptores de trabalhadores migrantes. Esses dois setores oferecem juntos 58\% dos empregos ocupados pelo grupo de trabalhadores migrantes nos municípios dinâmicos (TABELA 6).

Tabela 6: Distribuição relativa dostrabalhadoresnomercado formal por setor de atividade

\begin{tabular}{l|r|r|r|r}
\hline \multirow{2}{*}{\multicolumn{1}{c|}{ Setor }} & \multicolumn{2}{|c|}{ Total } & \multicolumn{2}{c}{ Migrantes } \\
\cline { 2 - 5 } & Dinâmicos & Demais & Dinâmicos & Demais \\
\hline Agropecuária & 5,5 & 3,6 & 6,6 & 5,5 \\
Extrativa Mineral & 1,0 & 0,3 & 1,4 & 0,5 \\
Construção Civil & 4,1 & 4,2 & 7,2 & 7,6 \\
Indústria & 25,8 & 16,3 & 25,5 & 18,5 \\
Serviços Industriais & 0,7 & 1,0 & 1,0 & 1,2 \\
Comércio & 18,4 & 17,2 & 16,9 & 16,7 \\
ServiçosAdministração & 25,3 & 31,8 & 32,5 & 38,0 \\
Pública & 18,7 & 25,0 & 8,8 & 12,0 \\
Outros/Ignorado & 0,4 & 0,6 & 0,0 & 0,0 \\
\hline Total & $\mathbf{1 0 0 , 0}$ & $\mathbf{1 0 0 , 0}$ & $\mathbf{1 0 0 , 0}$ & $\mathbf{1 0 0 , 0}$ \\
\hline
\end{tabular}

Fonte: MinistériodoTrabalho/RAIS

A maior presença de migrantes no mercado formal dos municípios dinâmicos se reflete em todos os setores, com destaque para construção civil, onde quase metade da mão-de-obra empregada no mercado formal é proveniente de outro município (TABELA 7). O que pode ser indício de importantes fluxos de mão-de-obra de baixa qualificação. 
Tabela 7: Participação dos trabalhadoresmigrantes no mercado formal dos municípios dinâmicos por setor de atividade

\begin{tabular}{l|r|r}
\hline \multirow{2}{*}{\multicolumn{1}{c|}{ Setor }} & \multicolumn{2}{|c}{ \%migrantes } \\
\cline { 2 - 3 } & $\begin{array}{c}\text { Municípios } \\
\text { Dinâmicos }\end{array}$ & $\begin{array}{c}\text { DemaisMu } \\
\text { nicípios }\end{array}$ \\
\hline Agropecuária & 31,1 & 29,7 \\
Extrativa Mineral & 35,8 & 32,0 \\
Construção Civil & 46,0 & 35,8 \\
Indústria & 25,6 & 22,2 \\
Serviços Industriais & 36,4 & 22,5 \\
Comércio & 23,8 & 19,1 \\
ServiçosAdministração & 33,3 & 23,5 \\
Pública & 12,2 & 9,5 \\
Outros/Ignorado & 0,0 & 0,0 \\
\hline Total & $\mathbf{2 5 , 9}$ & $\mathbf{1 9 , 6}$ \\
\hline
\end{tabular}

Fonte: MinistériodoTrabalho/RAIS

Quanto à escolaridade, observa-se uma situação favorável aos municípios "não-dinâmicos", nos quais é maior a presença de trabalhadores que possuem formação superior. Situação que também se repete quando se considera apenas os trabalhadores migrantes nos dois espaços.

Tabela 8: Distribuição relativa dostrabalhadores no mercado formal por nível de escolaridade

\begin{tabular}{l|r|r|r|r}
\hline \multirow{2}{*}{ Formação } & \multicolumn{2}{c|}{ Total } & \multicolumn{2}{c|}{ Migrantes } \\
\cline { 2 - 5 } & $\begin{array}{r}\text { Municípios } \\
\text { Dinâmicos }\end{array}$ & $\begin{array}{c}\text { DemaisMu } \\
\text { nicípios }\end{array}$ & $\begin{array}{c}\text { Municípios } \\
\text { Dinâmicos }\end{array}$ & $\begin{array}{c}\text { DemaisMu } \\
\text { nicípios }\end{array}$ \\
\hline Analfabeto & 1,6 & 1,3 & 1,1 & 0,8 \\
Fundamental incompleto & 28,9 & 25,1 & 25,7 & 22,5 \\
Fundamental Completo & 26,5 & 24,1 & 25,9 & 23,9 \\
Ensino Médio Completo & 34,9 & 35,0 & 37,3 & 39,5 \\
Superior Completo & 7,9 & 14,1 & 10,0 & 13,3 \\
Ignorado & 0,3 & 0,4 & 0,0 & 0,0 \\
\hline Total & 100,0 & 100,0 & 100,0 & 100,0 \\
\hline \hline
\end{tabular}

Fonte: MinistériodoTrabalho/RAIS

Entretanto, observando a participação intra-grupos de escolaridade, verifica-se que nos municípios dinâmicos a presença de migrantes é maior entre os trabalhadores mais escolarizados (superior completo), mas também entre os menos escolarizados (analfabetos e fundamental incompleto). O que pode apontar para dicotomias nesses mercados de trabalho. Que atraem tanto mão-de-obra mais qualificada quanto menos qualificada. É de se esperar que o dinamismo de algumas atividades impulsione toda uma cadeia produtiva, gerando vagas também em setores menos dependentes de qualificação da mão-de-obra, como o terciário inferior e a construção civil. 
TABELA 7: Participação dos trabalhadoresmigrantes no mercado formal dos municípios dinâmicos por nível de escolaridade

\begin{tabular}{|l|r|r}
\hline \multirow{2}{*}{\multicolumn{1}{c|}{ Formação }} & \multicolumn{2}{c}{ \%migrantes } \\
\cline { 2 - 3 } & $\begin{array}{c}\text { Municípios } \\
\text { Dinâmicos }\end{array}$ & $\begin{array}{c}\text { DemaisMu } \\
\text { nicípios }\end{array}$ \\
\hline Analfabeto & 18,7 & 12,6 \\
Fundamental incompleto & 23,0 & 17,6 \\
Fundamental Completo & 25,3 & 19,5 \\
Ensino Médio Completo & 27,7 & 22,1 \\
Superior Completo & 33,0 & 18,5 \\
Ignorado & 0,0 & 0,0 \\
\hline Total & $\mathbf{2 5 , 9}$ & $\mathbf{1 9 , 6}$ \\
\hline
\end{tabular}

Fonte: MinistériodoTrabalho/RAIS

\section{CONSIDERAÇÕESFINAIS}

O estudo permitiu constatar a existência de dois importantes vetores espaciais de dinamismo do mercado de trabalho formal. Primeiro na dimensão da rede urbana, onde se destacam os municípios do nível intermediário, incorporando pequenas e médias localidades. $\mathrm{O}$ segundo, de dimensão regional, destaca o dinamismo das regiões Norte e Centro Oeste. A indústria e a agropecuária figuram entre as atividades com maior contribuição para o dinamismo destas localidades, demonstrando que tal processo é sustentado pela expansão de atividades produtivas.

Não obstante as limitações da base de dados utilizada, as evidências apresentadas mostram que o dinamismo verificado faz aumentar a presença nesses municípios de trabalhadores "migrantes" no mercado formal. Foram identificados fluxos expressivos de mãode-obra em direção aos municípios dinâmicos do Centro Oeste e Norte, confirmando a importância da migração inter-regional.

Uma dicotomia foi destacada: os municípios dinâmicos tendem a atrair trabalhadores qualificados, como mostra a maior participação relativa de "migrantes" com formação superior, mas também trabalhadores de baixa qualificação, fazendo aumentar a participação relativa de trabalhadores analfabetos ou que não completaram o Ensino Fundamental. É se esperar que a expansão das atividades econômicas e do mercado formal necessite da "importação" de trabalhadores mais qualificados, o que não exclui a atração de trabalhadores de baixa qualificação para ocupações na construção civil e no "baixo" terciário.

resultados aqui apresentados mostram que muitas localidades intermediárias da rede urbana nacional experimentam recentemente processos de intenso crescimento do mercado de trabalho formal. Considerando que esse mercado é um bom indicador do nível das atividades econômicas, 
pode se esperar que esses lugares assumam papel fundamental no processo de reconfiguração espacial das atividades econômicas e da população no Brasil. Isso não só confirma a mudança do padrão migratório no Brasil contemporâneo, mas aponta novos e importantes espaços que estruturam mercados de trabalho locais nos quais é imprescindível a contribuição de brasileiros, geralmente detentores de experiências no trabalho formal, boa parte delas decorrente de trajetórias migracionais de longa data. 


\section{REFERÊNCIAS BIBLIOGRÁFICAS}

BECKER,Bertha.UmanovaregionalizaçãoparapensaroBrasil?In:LIMONAD,Ester, HAESBAERT,Rogério,MOREIRA,Ruy(orgs).BrasilséculoXXIporumanovaregionalização? Processos, escalas, agentes. São Paulo: MAX Limonad,2004.

BENKO,G.eLIPIETZ,A.OnovodebateRegional.In:BENKO,G.eLIPIETZ,A.(orgs.). Asregiõesganhadoras-distritoseredes:osnovosparadigmasdageografiaeconômica. Oieras: Celta Editora, 1994.

DENEGRI,JoãoAlbertoetalli.MercadoFormaldeTrabalho:ComparaçãoentreosMicrodadosdaRAI SedaPNAD.Textoparadiscussãon ${ }^{\circ}$ 440,IPEA,Brasília,novembrode 2001 (29 pág.)

GRAZIANODASILVA,José.ONovoRuralBrasileiro.2ª edCampinas,IE/UNICAMP, 1999.

MATOS,R.Questõesteóricasacercadosprocessosdeconcentraçãoedesconcentraçãodapopulaçãono espaço.In:RevistaBrasileiradeEstudosPopulacionais.SãoPaulo,v.13,p. 35-58, 1995.

MATOS,Ralfo.AcontribuiçãodosimigrantesemáreasdedesconcentraçãodemográficadoBrasilconte mporâneo.RevistaBrasileiradeEstudosdePopulação,Campinas,v.19,n.1, jan./jun. 2002.

PACHECO,CarlosA.Desconcentraçãoeconômicaefragmentaçãodaeconomianacional. Economia eSociedade, Campinas, (6): 113-40, jun. 1996.

RALLET,A.L'économiedeproximités",EtudesetRecherchessurlessystèmes développement, n³3, 11-25, 2003.

agrairesetle

SABÓIA,João.DescentralizaçãoindustrialnoBrasilnadécadadenoventa:umprocessodinâmicoedifer enciadoregionalmente.NovaEconomia,BeloHorizonte,v.11,n.2,p.85-122, dez. 2001.

SCOTT,A.J., AGNEW, J.,SOJA,E.W. \&STORPER,M.Cidades-regiõesglobais.Espaço\& Debates n ${ }^{\circ}$ 41, São Paulo: Núcleo de estudos regionais eurbanos, 2001.

TINOCO,A.C..IntegraçãoouFragmentação:OImpassegeradopeloFetichismodaDesconcentração. Espaço \& Debates, São Paulo, n. 41, p. 46-65, 2001.

TORRE,André.Desenvolvimentolocalerelaçõesdeproximidade.Interações-Revista Internacional do Desenvolvimento Local, v. 4,n. 7,p. 27-39, set. 2003

VELTZ,P.Hierarquiaeredes.In:BENKO,G.eLIPIETZ,A.(orgs.).Asregiõesganhadorasdistritoseredes:osnovosparadigmasdageografiaeconômica.Oieras:CeltaEditora, 1994. 